Article

\title{
Theoretical and Economic Evaluation of Low-Cost Deep Eutectic Solvents for Effective Biogas Upgrading to Bio-Methane
}

\author{
Edyta Słupek (1), Patrycja Makoś * (1) and Jacek Gębicki \\ Department of Process Engineering and Chemical Technology, Faculty of Chemistry, Gdansk University of \\ Technology, G. Narutowicza St. 11/12,80-233 Gdansk, Poland; edyta.slupek@pg.edu.pl (E.S.); \\ jacek.gebicki@pg.edu.pl (J.G.) \\ * Correspondence: patrycja.makos@pg.edu.pl; Tel.: +48-508997100
}

Received: 29 May 2020; Accepted: 28 June 2020; Published: 1 July 2020

check for updates

\begin{abstract}
This paper presents the theoretical screening of 23 low-cost deep eutectic solvents (DESs) as absorbents for effective removal of the main impurities from biogas streams using a conductor-like screening model for real solvents (COSMO-RS). Based on thermodynamic parameters, i.e., the activity coefficient, excess enthalpy, and Henry's constant, two DESs composed of choline chloride: urea in a 1:2 molar ratio (ChCl:U 1:2), and choline chloride: oxalic acid in a 1:2 molar ratio (ChCl:OA 1:2) were selected as the most effective absorbents. The $\sigma$-profile and $\sigma$-potential were used in order to explain the mechanism of the absorptive removal of $\mathrm{CO}_{2}, \mathrm{H}_{2} \mathrm{~S}$, and siloxanes from a biogas stream. In addition, an economic analysis was prepared to demonstrate the competitiveness of new DESs in the sorbents market. The unit cost of $1 \mathrm{~m}^{3}$ of pure bio-methane was estimated to be in the range of 0.35-0.37 EUR, which is comparable to currently used technologies.
\end{abstract}

Keywords: biogas; deep eutectic solvents; upgrading; absorption; COSMO-RS; economic analysis

\section{Introduction}

Due to European Union (EU) energy policies to promote the utilization of renewable resources, there has been a significant increase in biogas plants and the level of biogas production [1,2]. The number of biogas plant installations and the amount of produced bio-methane in recent years is presented in detail in Figure 1. Biogas can be produced by anaerobic digestion from different waste materials (i.e., manure and food residue, wastewater sludge, or industrial by-products) or landfill gas. Biogas mainly consists of methane (50-70\%) and contaminants including carbon dioxide, water, nitrogen, oxygen, hydrogen sulfide, ammonia, and numerous organic compounds (i.e., siloxanes) [3-5]. The presence of these contaminants prevents the use of biogas as an alternative transport fuel or natural gas substitute. Among the biogas impurities, carbon dioxide, hydrogen sulfide and siloxanes are the most problematic $[6,7]$.

Carbon dioxide is present in high concentrations in biogas and it acts as a ballast; this significantly reduces the quality of biogas because it reduces the caloric power of biogas in proportion to its concentration. Biogas should contain more than $90 \%$ pure methane, depending on its further application. During the biogas combustion process, hydrogen sulfide reacts with water, forming sulfuric acid, which corrodes the surface in the combustion chamber [8], while the siloxanes are converted into silicon dioxide $\left(\mathrm{SiO}_{2}\right)$, which can be deposited into the cylinder, impeller, valves, piston rings, liners, spark plugs, and turbochargers. Accumulation of hard deposits of $\mathrm{SiO}_{2}$ reduces the life span of the turbines and engine efficiency, which results in detonation in the combustion chambers and an increase in the exhaust gas emissions due to unburned fuel. This also results in higher plant maintenance costs. In addition, the presence of certain groups of trace compounds in biogas can cause 
the emission of toxic by-products into the atmosphere. The occurrence of these contaminants is a major barrier to the use of biogas as a renewable energy source.

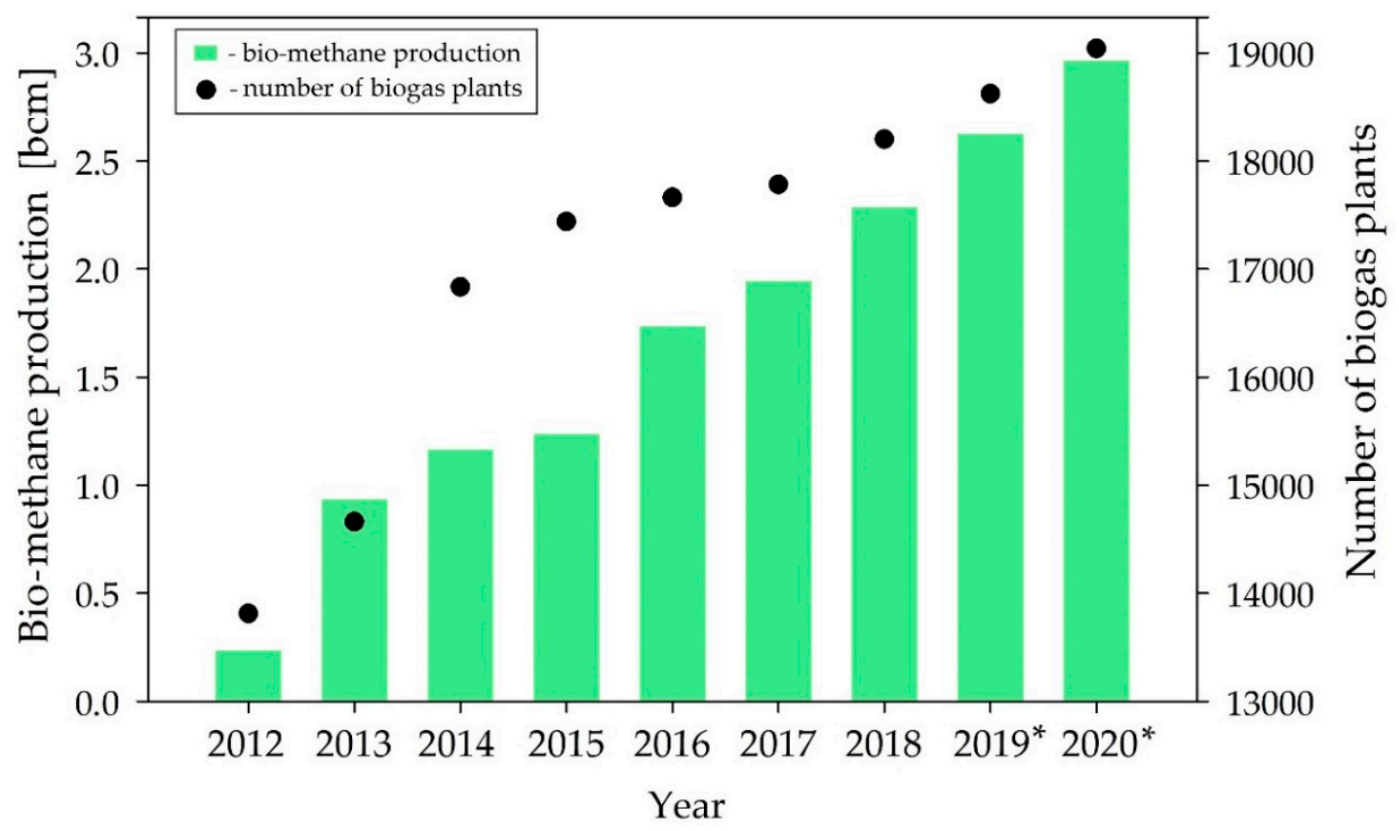

Figure 1. Number of biogas plants and bio-methane production from 2012 to 2020 in the European Union (bcm-billion cubic meters; 2019* and 2020* are estimated values).

Currently, there are several technologies for removing $\mathrm{CO}_{2}, \mathrm{H}_{2} \mathrm{~S}$, and siloxanes from biogas including adsorption, refrigeration with condensation, membrane technologies, biological methods, and absorption [9-13]. Among these technologies, physical absorption is one of the most popular. This process consists of transferring contaminants from a gas phase to an absorbent. Different types of absorbents such as water, organic compounds, and oils are used [14-16]. However, there are a few disadvantages associated with conventional organic absorbents, which can lead to equipment corrosion and harmful effects on the environment. Therefore, in the past decade, ionic liquids (ILs) have been proposed as a potential alternative for conventional absorbents for $\mathrm{CO}_{2}$ [17-20] and $\mathrm{H}_{2} \mathrm{~S}$ [17,21-23] removal from different type of gas streams. Despite the attractive physicochemical properties of ILs (i.e., good thermal stability, non-volatile properties, and high absorption capacity [24,25]), they not found practical industrial application due to their high viscosity, potential toxicity, high cost and complicated synthesis processes [26]. Due to the limitations of both conventional solvents and ILs, alternative solutions are still in demand. Nowadays, one of the most promising group of green absorbents is deep eutectic solvents (DESs). DESs are synthesized by the direct mixing of two ingredients-hydrogen bond acceptor (HBA) with a hydrogen bond donor (HBD). DES mixtures are characterized by a lower melting point compared to the individual components [27]. In addition, DESs are characterized by specific physicochemical properties such as their non-volatility, non-flammability, high absorption capacity, non-toxic character, and high thermal stability [28,29]. A comparison of the properties of DES with other absorbents is presented in Table 1. 
Table 1. Comparison of physicochemical properties of absorbents [28-37].

\begin{tabular}{|c|c|c|c|c|}
\hline Properties & Water & Organic Amine & ILs & DESs \\
\hline The synthesis & No & No & $\begin{array}{l}\text { Multi-step } \\
\text { synthesis }\end{array}$ & Easy \\
\hline Applicability & Single function & Single function & Multifunction & Multifunction \\
\hline Tunability & No & No & High & High \\
\hline Thermal stability & Low & Low & $\begin{array}{l}\text { Tunable, but } \\
\text { generally high }\end{array}$ & $\begin{array}{l}\text { Tunable, but } \\
\text { generally high }\end{array}$ \\
\hline Boiling Points & $100^{\circ} \mathrm{C}$ & $111-350{ }^{\circ} \mathrm{C}$ & $>250{ }^{\circ} \mathrm{C}$ & $\begin{array}{c}\text { Higher than other } \\
\text { solvents } \\
\left(214-1774{ }^{\circ} \mathrm{C}\right)\end{array}$ \\
\hline $\begin{array}{l}\text { Environmentally } \\
\text { friendly }\end{array}$ & Yes & No & Not all & Yes \\
\hline Toxicity & No & Yes & $\begin{array}{l}\text { Often increase } \\
\text { toxicity for aquatic } \\
\text { systems }\end{array}$ & $\begin{array}{l}\text { Acceptable toxicity } \\
\text { profiles }\end{array}$ \\
\hline Corrosive nature & High & High & Low & Low \\
\hline Biodegradability & Readily & Readily & Difficult & Readily \\
\hline Density & Low & Medium & $\begin{array}{l}\text { Tunable, but } \\
\text { generally higher } \\
\text { than other solvents }\end{array}$ & $\begin{array}{c}\text { Tunable, but } \\
\text { generally lower } \\
\text { than ILs }\end{array}$ \\
\hline Viscosity & Low & Medium & $\begin{array}{l}\text { Tunable, but } \\
\text { generally higher } \\
\text { than other solvents }\end{array}$ & $\begin{array}{c}\text { Tunable, but } \\
\text { generally lower } \\
\text { than ILs }\end{array}$ \\
\hline Surface tension & High & Low & $\begin{array}{c}\text { Generally lower } \\
\text { than water and } \\
\text { higher than organic } \\
\text { amine }\end{array}$ & Low \\
\hline Vapor pressure & High & High & Low & Low \\
\hline Flammability & No & Yes & No & No \\
\hline Nature & Neutral & Basic & Basic/neutral/acid & Basic/neutral/acid \\
\hline Type of absorption & Physical & Chemical/Physical & Physical & Physical \\
\hline $\begin{array}{c}\text { Absorption } \\
\text { capacity }\end{array}$ & Medium & Medium & High & High \\
\hline Biodegradable & Yes & No & Poor & Yes \\
\hline Cost & Low & Moderate & High & Low \\
\hline
\end{tabular}

Because of their unique properties, DESs are now successfully used as extractants [38-41] and absorption solvents [42-46] for the purification of gas and liquid streams [46-49]. Of the available DESs, solvents composed of quaternary ammonium salts are considered to be the most promising absorbents. DESs can also be synthesized from natural compounds, which makes them so-called "green solvents" due to the lack of or very low toxicity and their biodegradability [50]. Due to the high thermal stability of DESs, they can be regenerated repeatedly without loss of absorption capacity and the regeneration step requires less energy compared to other popular absorbents. Hence, the use of DESs as absorption solvents in the biogas upgrading process are considered as environmentally friendly technologies for the production of green bio-energy.

The application of upgraded biogas for the production of energy is considered as one of the most efficient methods for reducing greenhouse gas emissions to the atmosphere. For this reason, 23 deep eutectic solvents composed of quaternary ammonium salts and low-cost organic components were examined as potential absorbents for the removal of siloxanes, $\mathrm{CO}_{2}$, and $\mathrm{H}_{2} \mathrm{~S}$ from a model biogas stream. A conductor-like screening model for real solvents (COSMO-RS) was used for the pre-selection of DESs. The selection of DESs with the highest dissolution potential for all impurities was made on the basis of the activity coefficient, excess enthalpy, and Henry's constant values. The absorption mechanism for the removal of the main impurities $\left(\mathrm{CO}_{2}, \mathrm{H}_{2} \mathrm{~S}\right.$, siloxanes) was explained based on $\sigma$-profiles and $\sigma$-potential analysis. In addition, an economic analysis of the biogas upgrading processes 
was prepared. To the best of our knowledge, this is the first economic analysis report dedicated to biogas upgrading processes that use DESs.

\section{Materials and Methods}

\subsection{Procedures}

\subsubsection{Computational Studies}

In this investigation, COSMO-RS calculations were carried out using ADF COSMO-RS software (SCM, Netherlands). The geometry optimization of all DESs were performed using the continuum solvation COSMO model at the BVP86/TZVP level of theory. This level of theory was selected due to proven high efficiency and low computational costs [51]. The list of 23 DESs is presented in Table 2. The main thermodynamic parameters, i.e., the activity coefficient, excess enthalpy, and Henry's constant were calculated based on previous studies $[52,53]$. The parameters were determined for model biogas composed of $64.9 \%$ of $\mathrm{CH}_{4}, 31 \%$ of $\mathrm{CO}_{2}, 3 \%$ of $\mathrm{H}_{2} \mathrm{O}$ and 1.04 of $\mathrm{H}_{2} \mathrm{~S}$, and $0.02 \%$ of hexamethyldisiloxane (L2), octamethyltrisiloxane (L3), and octamethylcyclotetrasiloxaan (D4), which represents the typical composition of biogas from wastewater treatment plants and landfills $[8,54]$.

Table 2. List of deep eutectic solvents (DESs) used for the conductor-like screening model for real solvents (COSMO-RS) calculation.

\begin{tabular}{ccccc}
\hline No. & HBA & HBD & HBA:HBD Molar Ratio & Abbreviation \\
\hline 1 & Choline chloride & ethylene glycol & $1: 3$ & ChCl:EG (1:3) \\
2 & Choline chloride & glycerol & $1: 3$ & ChCl:Gly (1:3) \\
3 & Choline chloride & levulinic acid & $1: 3$ & ChCl:Lev (1:3) \\
4 & Choline chloride & lactic acid & $1: 2$ & ChCl:LA (1:2) \\
5 & Choline chloride & butyric acid & $1: 2$ & ChCl:Bu (1:2) \\
6 & Choline chloride & phenol & $1: 2$ & ChCl:Ph (1:2) \\
7 & Choline chloride & urea & $1: 2$ & ChCl:U (1:2) \\
8 & Choline chloride & diethylene glycol & $1: 2$ & ChCl:DEG (1:2) \\
9 & Choline chloride & oxalic acid & $1: 2)$ \\
10 & Choline chloride & methacrylic acid & $1: 2$ & ChCl:MthA (1:2) \\
11 & Choline chloride & propylene glycol & $1: 2$ & ChCl:PG (1:2) \\
12 & Tetrabutylammonium chloride & ethylene glycol & $1: 3$ & TBACl:EG (1:3) \\
13 & Tetrabutylammonium chloride & glycerol & $1: 3$ & TBACl:Gly (1:3) \\
14 & Tetrabutylammonium chloride & levulinic acid & $1: 3$ & TBACl:Lev (1:3) \\
15 & Tetrabutylammonium chloride & lactic acid & $1: 2$ & TBACl:LA (1:2) \\
16 & Tetrabutylammonium chloride & butyric acid & $1: 2$ & TBACl:Bu (1:2) \\
17 & Tetrabutylammonium chloride & phenol & TBACl:Ph (1:2) \\
18 & Tetrapropylammonium bromide & ethylene glycol & TEABr:EG (1:3) \\
19 & Tetrapropylammonium bromide & glycerol & $1: 3$ & TEABr:Gly (1:3) \\
20 & Tetrapropylammonium bromide & levulinic acid & $1: 3$ & TEABr:Lev (1:3) \\
21 & Tetrapropylammonium bromide & lactic acid & $1: 3$ & TEABr:LA (1:2) \\
22 & Tetrapropylammonium bromide & butyric acid & $1: 2$ & TEABr:Bu (1:2) \\
23 & Tetrapropylammonium bromide & phenol & $1: 2$ & TBABr:Ph (1:2) \\
\hline
\end{tabular}

Henry's constant $\left(K_{H}\right)$ was applied to systems in thermodynamic equilibrium. The $K_{H}$ links the solubility of solute impurities (i) to its partial pressure above the mixture $\left(p_{i}^{\text {vap }}\right) . K_{H}$ was calculated using Equation (1).

$$
K_{H}=\frac{1}{\gamma_{i} p_{i}^{v a p}}
$$

where $\gamma_{i}$ is the infinite dilute activity coefficient of impurities $(i)$, and $p_{i}^{v a p}$ is the vapor pressure of impurities (i). 
The activity coefficient was calculated using Equation (2) and Equation (3).

$$
\ln \left(\gamma_{i}\right)=\frac{\mu_{i}^{\text {solv }}-\mu_{i}^{\text {pure }}}{R T}
$$

where $\mu_{i}^{p}$ is the chemical potential of pure impurities $(i), \mu_{i}^{j}$ is the chemical potential of impurities in the liquid phase, $T$ is the temperature $(\mathrm{K})$, and the universal gas constant $R=8.314 \mathrm{~J} / \mathrm{mol}$.

The excess enthalpy of mixtures $H^{E}(\mathrm{~kJ} / \mathrm{mol})$ was calculated based on Gibbs-Helmholtz using Equation (3).

$$
H^{E}=-T^{2} \frac{\partial\left(\frac{G^{E}}{T}\right)}{\partial T}
$$

where $T$ is the temperature $(\mathrm{K})$, and $G^{E}$ is the excess Gibbs free energy $(\mathrm{kJ} / \mathrm{mol})$.

\subsubsection{Biogas Upgrading Technology Description}

The scheme for the biogas upgrading technology described in this paper is presented in Figure 2. The physicochemical properties of DESs are similar to the most commonly used absorbents (i.e., amine or water), therefore, DESs can be applied in existing and currently used absorption installations. In order to better compare the benefits of DESs application in the absorption process, the size of the installations (absorption and desorption column, compressor, pump, blower, dryer, and heat exchangers) and the process streams (inlet biogas stream $813 \mathrm{~m}^{3} / \mathrm{h}$ and inlet air stream $403 \mathrm{~m}^{3} / \mathrm{h}$ ) was adopted from previous studies $[55,56]$.

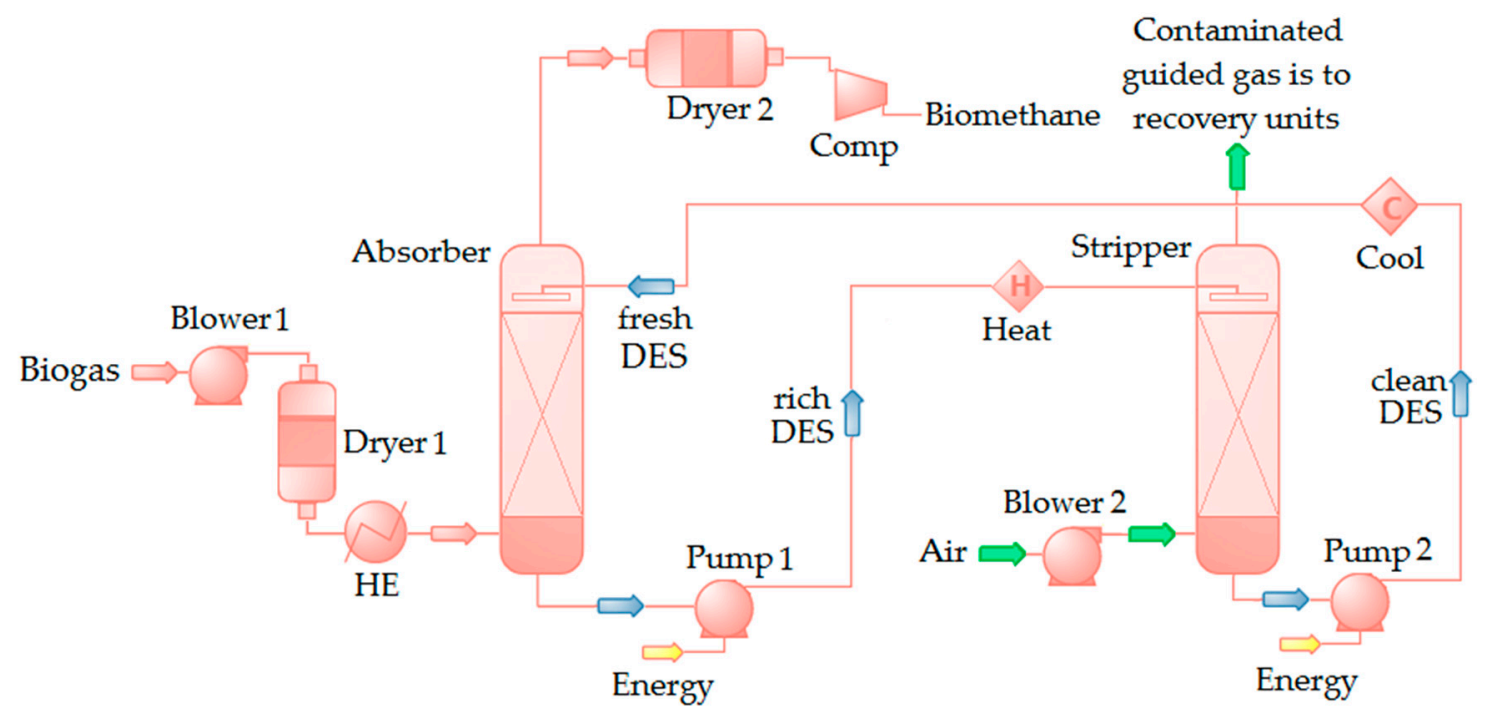

Figure 2. Scheme for the biogas upgrading technology $[55,56]$.

In the first stage, biogas stream is introduced into Dryer 1 . Then, the biogas is passed directly to the heat exchanger, after which biogas is directed into the bottom part of the absorber $\left(813 \mathrm{~m}^{3} / \mathrm{h}\right)$, which operates at a temperature of $20^{\circ} \mathrm{C}$, and pressure of $100 \mathrm{kPa}$. The biogas stream is introduced at the bottom of the absorber. The DES is introduced at the top of the column. The biogas and DES move through a counter-flow scrubbing column. In the column, the biogas comes into contact with a DES to dissolve the main impurities ( $\mathrm{L} 2, \mathrm{~L} 3, \mathrm{D} 4, \mathrm{CO}_{2}$, and $\mathrm{H}_{2} \mathrm{~S}$ ). This is a process of mass transfer of pollutants from the biogas phase to the liquid DES phase. The upgraded bio-methane is downloaded from the top of the absorber, drained again (Dryer 2), and compressed. The obtained renewable bio-methane can be directly injected into the distribution gas grid at $700 \mathrm{kPa}$. The biogas purification system also contains the stripper column, which is operated under a temperature of $115-125^{\circ} \mathrm{C}$ and pressure of $140-170 \mathrm{kPa}$. Saturated DES from the absorption column is directed into the stripper column where 
DES is purged with an inlet air stream $\left(403 \mathrm{~m}^{3} / \mathrm{h}\right.$ ). Most of the impurities (L2, L3, D4, $\mathrm{CO}_{2}$, and $\mathrm{H}_{2} \mathrm{~S}$ ) are liberated into a concentrated air stream that exits at the top of the stripper column. The impurities stream is directed to the $\mathrm{H}_{2} \mathrm{~S}, \mathrm{CO}_{2}, \mathrm{~L} 2, \mathrm{~L} 3$, and D4 recovery system. The regenerated DES is cooled and returned to the absorber column.

\subsubsection{Cost and Economic Analysis}

The cost simulations included an estimation of the total annual cost (TAC) of the biogas upgrading process. TAC included the annual capital investment cost $(A C I C)$, and the annual operation and maintenance cost (OC and MC).

The ACIC was estimated based on the method of Scholz et al. [57] according to Equation (4).

$$
A C I C=\operatorname{TCIC} \frac{i(1+i)^{n}}{(1+i)^{n}-1}
$$

where $A C I C$ is the annual capital investment cost, TCIC is the total capital investment cost, $i$ is the interest rate ( $9 \%)$, and $n$ is the depreciation period (15 years).

The TCIC was mainly estimated as the percentage value of the equipment cost (EC) [55]. The EC was estimated by Guthrie's method [58], according to Equation (5).

$$
E C=\operatorname{PEC}\left(f_{m p}+f_{m}-1\right)
$$

where $E C$ is the equipment cost, $P E C$ is the bare purchased equipment cost, $f_{m p}$ the material and pressure correction factor, and $f_{m}$ is the module factor, which depends on the size equipment. The values of $f_{m p}$ and $f_{m}$ were adopted according to the procedure proposed by Scholz et al. [57]. The EC of the absorption column, stripper column, blowers, pumps, compressors, and heat exchangers was adopted from other studies [56]. The list of basic parameters for maintenance and operation cost, which consist of operating supply cost, research, and development (R\&D) costs, personnel labor cost, utility costs (i.e., electricity cost for heating and cooling, absorbent exchange cost) is presented in Table 3.

Table 3. Parameters for operation costs.

\begin{tabular}{cccc}
\hline Parameter & Units & Costs & Ref. \\
\hline Electricity & EUR/kWh & 0.1 & {$[59]$} \\
Heat & EUR/kWh & 0.046 & {$[57]$} \\
Personnel & EUR/h & 38.88 & {$[56]$} \\
Choline chloride & EUR/t & 4550 & {$[60]$} \\
Urea & EUR/t & 218.4 & {$[61]$} \\
Oxalic acid & EUR/t & 455 & {$[62]$} \\
\hline
\end{tabular}

The last step of the cost analysis was the estimation of the risk and economic benefits of the project. The financial assessment of the investment was carried out on the basis of the expected energy production, and total costs of the plant. The unit cost (UC) of $1 \mathrm{~m}^{3}$ biogas purification was calculated according to Equation (6) [63].

$$
U C=\left(\frac{\left(\frac{T C I C}{n}\right)+((T C I C * i)+T A C)}{A P B}\right)
$$

where $U C$ is the unit cost of $1 \mathrm{~m}^{3}$ bio-methane, $i$ is the interest rate $(9 \%), n$ is the depreciation period (15 years), APB is the annual production of bio-methane $\left[\mathrm{m}^{3}\right]$, and $T A C$ is the total annual cost.

The annual amount of cubic meters of upgraded biogas stream was determined according to Equation (7).

$$
A P B=B F \cdot \% \mathrm{CH}_{4} \cdot \mathrm{ML}
$$


where $\mathrm{BF}$ is the biogas flow, $\% \mathrm{CH}_{4}$ is the percentage of methane in biogas, and $M L$ is the methane loss.

\section{Results and Discussion}

\subsection{COSMO-RS Prediction-Pre-Selection of DESs}

The preselection of DESs that are characterized by high solubility of siloxanes, $\mathrm{H}_{2} \mathrm{~S}, \mathrm{CO}_{2}, \mathrm{H}_{2} \mathrm{O}$, and $\mathrm{CH}_{4}$ was made based on the Henry's constants, activity coefficients, and excess enthalpy of mixtures that were predicted according to the COSMO-RS method. Water was omitted in the calculations because it was assumed to be removed before the biogas enters the absorption column. All parameters were determined at $20^{\circ} \mathrm{C}$ and $100 \mathrm{kPa}$. The calculation results are presented in Table 4 .

The activity coefficient is a thermodynamic parameter that is associated with the affinity of siloxanes, $\mathrm{H}_{2} \mathrm{~S}, \mathrm{CO}_{2}$, and $\mathrm{CH}_{4}$ to DESs. This parameter indicates the differences in strength among DESs and impurities, which are a result of the dominant interactions. Usually, the activity coefficient values are given as $\ln (1 / \gamma)$, hence these are rather negative (Table 4) [64]. The higher negative values of logarithmic activity coefficients indicate greater solubility of siloxanes, $\mathrm{H}_{2} \mathrm{~S}$, and $\mathrm{CO}_{2}$ in DESs. The second main thermodynamic parameter is the excess enthalpy of mixtures $\left(H^{E}\right) . H^{E}$ is a sensitive measure of the intermolecular interactions between DESs and impurities. The results of $\mathrm{H}^{\mathrm{E}}$ calculated for all DES-impurities models are presented in Table 4. The DES, which is characterized by a higher dissolution capacity of $\mathrm{CO}_{2}, \mathrm{H}_{2} \mathrm{~S}$, and siloxanes has lower values of $H^{E}$ (higher negative). The third parameter is the Henry's Law constant $\left(K_{H}\right)$. The $K_{H}$ describes the ratio at the equilibrium of the concentration of impurities in the gas phase to the concentration of impurities in the DES phase, and it combines vapor pressure and solubility, which can be used to estimate the likelihood that a substance will be exchanged between the gas phase and a DES. Lower $K_{H}$ indicates a higher concentration of impurities in the DES phase than in the gas phase.

$\mathrm{ChCl}: \mathrm{U}(1: 2)$ and $\mathrm{ChCl}: \mathrm{OA}(1: 2)$ showed lower values for all thermodynamic parameters, relative to all impurities. Slightly higher values were obtained for the rest of the DESs composed of choline chloride such as HBA. This indicates that this type of HBA in DES structures has a major influence on absorption efficiency. This is in line with the conclusions obtained in previous studies [46]. This can be caused by several factors, including HBA alkyl chain length, different charge density on the ammonium, as well as asymmetry in $\mathrm{ChCl}$ ammonium with a hydroxyl group in the longest branch, and theoretically, a type of counter-ion $\left(\mathrm{Cl}^{-}\right.$or $\left.\mathrm{Br}^{-}\right)$. However, the obtained results indicate that this type of counter-ion in HBA only has a slight effect on the ability of DESs to dissolve all impurities. The use of DESs containing $\mathrm{ChCl}$ as HBA in the absorption process is preferred because they are characterized by less viscosity compared to DESs composed of quaternary ammonium salts with long alkyl chain length [65].

Principal components analysis (PCA) was used to obtain a better interpretation of all results (the activity coefficient, excess enthalpy, and Henry's constant). The PCA plot is presented in Figure 3. The numbers on the diagram correspond to the DESs numbers in Table 4. The results indicate that DESs can be divided into three groups. The first group is marked with a yellow circle and contains two DESs (ChCl:U 1:2 and ChCl:OA 1:2) that have the greatest dissolution potential for all impurities. The second group, marked with a green circle, includes DESs that have the potential to effectively absorb siloxanes, but they have low $\mathrm{CO}_{2}$ and $\mathrm{H}_{2} \mathrm{~S}$ dissolution potential. These DESs may have potential use for selective siloxane removal, but their solubility is insufficient in applications that require the comprehensive removal of impurities from biogas. The last group includes DESs that have the lowest absorption potential for all of the tested compounds. 
Table 4. The logarithmic activity coefficient of siloxanes $\mathrm{H}_{2} \mathrm{~S}$, and $\mathrm{CO}_{2}$ model at infinite dilution, excess enthalpy of mixtures and Henry's constant of siloxanes calculated by COSMO-RS at $20^{\circ} \mathrm{C}$ and $101325 \mathrm{~Pa}$.

\begin{tabular}{|c|c|c|c|c|c|c|c|c|c|c|c|c|c|c|c|c|}
\hline \multirow{2}{*}{ No. } & \multirow{2}{*}{ DES } & \multicolumn{5}{|c|}{ Activity Coefficient } & \multicolumn{5}{|c|}{$H^{E}[\mathrm{~kJ} / \mathrm{mol}]$} & \multicolumn{5}{|c|}{$K_{H}[\mathrm{~mol} / \mathrm{L} \mathrm{atm}]$} \\
\hline & & L2 & L3 & D4 & $\mathrm{H}_{2} \mathrm{~S}$ & $\mathrm{CO}_{2}$ & L2 & L3 & D4 & $\mathrm{H}_{2} \mathrm{~S}$ & $\mathrm{CO}_{2}$ & L2 & $\begin{array}{c}\mathrm{L3} \\
{\left[{ }^{*} 10^{3}\right]}\end{array}$ & $\begin{array}{c}\text { D4 } \\
{\left[{ }^{*} 10^{5}\right]}\end{array}$ & $\mathrm{H}_{2} \mathrm{~S}$ & $\mathrm{CO}_{2}$ \\
\hline 1 & ChCl:EG (1:3) & -5.28 & -6.81 & -6.57 & -0.30 & -1.09 & -5.58 & -5.57 & -5.57 & -5.62 & -5.61 & 50.8 & 1.25 & 3.12 & 1.79 & 0.089 \\
\hline 2 & ChCl:Gly (1:3) & -4.86 & -6.30 & -6.03 & -0.08 & -0.83 & -5.63 & -5.62 & -5.62 & -5.68 & -5.66 & 76.2 & 2.22 & 5.67 & 1.80 & 0.093 \\
\hline 3 & ChCl:Lev (1:3) & -3.68 & -4.77 & -4.42 & 0.16 & -0.54 & -5.68 & -5.68 & -5.68 & -5.73 & -5.71 & 151.3 & 5.67 & 15.49 & 1.90 & 0.104 \\
\hline 4 & ChCl:LA (1:2) & -5.49 & -7.12 & -6.81 & -0.39 & -1.14 & -7.45 & -7.44 & -7.44 & -7.48 & -7.46 & 33.0 & 0.74 & 1.95 & 1.36 & 0.070 \\
\hline 5 & $\mathrm{ChCl:Bu} \mathrm{(1:2)}$ & -3.13 & -4.04 & -3.66 & 0.01 & -0.54 & -7.52 & -7.51 & -7.52 & -7.53 & -7.52 & 383.8 & 18.57 & 52.76 & 1.89 & 0.119 \\
\hline 6 & $\mathrm{ChCl}: \mathrm{Ph}(1: 2)$ & -3.24 & -4.19 & -3.49 & -0.14 & -0.63 & -7.77 & -7.77 & -7.82 & -7.33 & -7.76 & 366.3 & 17.29 & 69.11 & 1.59 & 0.107 \\
\hline 7 & ChCl:U (1:2) & -8.11 & -10.52 & -10.22 & -1.15 & -2.05 & -7.29 & -7.28 & -7.30 & -7.32 & -7.31 & 1.9 & 0.02 & 0.05 & 0.83 & 0.037 \\
\hline 8 & ChCl:DEG (1:2) & -4.30 & -5.57 & -5.32 & -0.11 & -0.75 & -7.65 & -7.64 & -7.63 & -7.69 & -7.67 & 97.5 & 3.17 & 7.94 & 1.49 & 0.086 \\
\hline 9 & ChCl:OA (1:2) & -8.11 & -10.55 & -9.43 & -1.01 & -1.88 & -8.09 & -8.08 & -8.18 & -8.12 & -8.10 & 3.8 & 0.04 & 0.24 & 0.82 & 0.038 \\
\hline 10 & ChCl:MthA (1:2) & -3.45 & -4.45 & -3.98 & -0.07 & -0.62 & -7.50 & -7.50 & -7.51 & -7.52 & -7.50 & 332.3 & 15.20 & 45.62 & 1.82 & 0.114 \\
\hline 11 & ChCl:PG (1:2) & -3.96 & -5.10 & -4.80 & -0.01 & -0.66 & -7.77 & -7.77 & -7.76 & -7.81 & -7.79 & 203.7 & 7.94 & 20.31 & 2.06 & 0.118 \\
\hline 12 & TBACl:EG (1:3) & -3.39 & -4.36 & -4.12 & 0.18 & -0.43 & -4.13 & -4.13 & -4.13 & -5.62 & -5.61 & 367.9 & 18.13 & 45.69 & 2.04 & 0.120 \\
\hline 13 & TBACl:Lev (1:3) & -2.30 & -2.97 & -2.64 & 0.47 & -0.09 & -4.13 & -4.13 & -4.13 & -5.73 & -5.71 & 640.4 & 39.82 & 107.48 & 2.02 & 0.127 \\
\hline 14 & TBACl:LA (1:2) & -2.97 & -3.83 & -3.53 & 0.43 & -0.11 & -5.35 & -5.35 & -5.35 & -5.38 & -5.35 & 601.2 & 36.54 & 98.86 & 1.96 & 0.125 \\
\hline 15 & TBACl:Bu (1:2) & -1.42 & -1.81 & -1.49 & 0.38 & -0.08 & -5.49 & -5.49 & -5.50 & -5.50 & 5.48 & 1413.2 & 109.25 & 293.16 & 2.10 & 0.146 \\
\hline 16 & TBACl:Ph (1:2) & -1.32 & -1.69 & -1.17 & 0.15 & -0.18 & -5.87 & -5.88 & -5.91 & -5.84 & -5.82 & 1579.3 & 125.21 & 423.11 & 1.63 & 0.128 \\
\hline 17 & TBABr:EG (1:3) & -3.46 & -4.45 & -4.18 & 0.12 & -0.44 & -3.85 & -3.85 & -3.85 & -5.32 & -5.30 & 334.4 & 16.01 & 41.41 & 1.90 & 0.118 \\
\hline 18 & TBABr:Gly (1:3) & -3.28 & -4.25 & -3.95 & 0.21 & -0.34 & -3.67 & -3.66 & -3.66 & -5.37 & -5.36 & 321.7 & 15.68 & 41.48 & 1.77 & 0.112 \\
\hline 19 & TBABr:Lev (1:3) & -2.35 & -3.04 & -2.70 & 0.41 & -0.10 & -3.85 & -3.85 & -3.85 & -5.43 & -5.42 & 593.7 & 36.09 & 98.92 & 1.89 & 0.125 \\
\hline 20 & TBABr:LA (1:2) & -3.03 & -3.92 & -3.59 & 0.03 & -0.50 & -4.97 & -4.53 & -4.98 & -5.00 & -4.98 & 261.8 & 11.87 & 32.05 & 1.56 & 0.101 \\
\hline 21 & TBABr:Bu (1:2) & -1.44 & -1.84 & -1.48 & 0.32 & -0.08 & -5.10 & -5.10 & -4.75 & -5.11 & -5.09 & 1386.6 & 106.58 & 295.07 & 1.97 & 0.145 \\
\hline 22 & TBABr:Ph (1:2) & -1.32 & -1.70 & -1.10 & 0.13 & -0.18 & -5.43 & -5.44 & -5.48 & -5.39 & -5.38 & 1567.8 & 124.03 & 449.89 & 1.60 & 0.129 \\
\hline
\end{tabular}




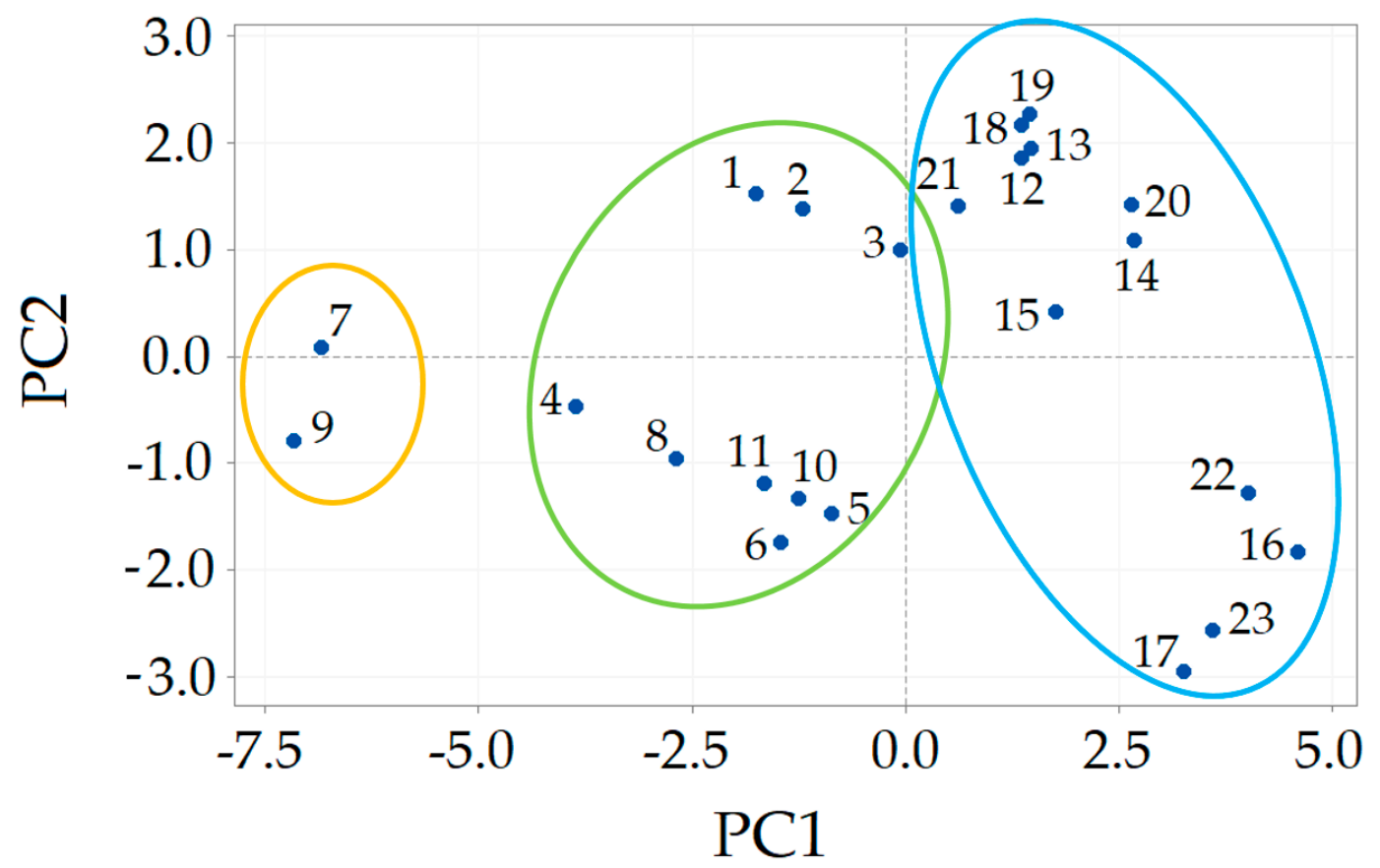

Figure 3. Principal components analysis (PCA) plot of all thermodynamic data including the activity coefficient, excess enthalpy and Henry's constant.

Based on the obtained thermodynamic results, only the DESs that showed the greatest dissolution potential for all impurities were adopted for further consideration (ChCl:U 1:2 and ChCl:OA 1:2). In practice, most of the obtained results using COSMO-RS are slightly overestimated, and this fact was more pronounced for temperatures far from room temperature. Due to the fact that all calculations were made for $20^{\circ} \mathrm{C}$, it can be concluded that the obtained results are very reliable, because the COSMO-RS model ensures acceptable accuracy (about 5\%) with regard to experimental results [66,67].

\subsection{Molecular Interactions}

After geometric optimization, the absorption efficiency of DESs can be interpreted by molecular interactions. The geometric optimized structures of DESs are presented in Figure 4. Based on molecule-specific characteristics, the charge-related $\sigma$-profiles and $\sigma$-potential were successfully used to interpret the complex molecular interactions, according to previous studies [68-70].

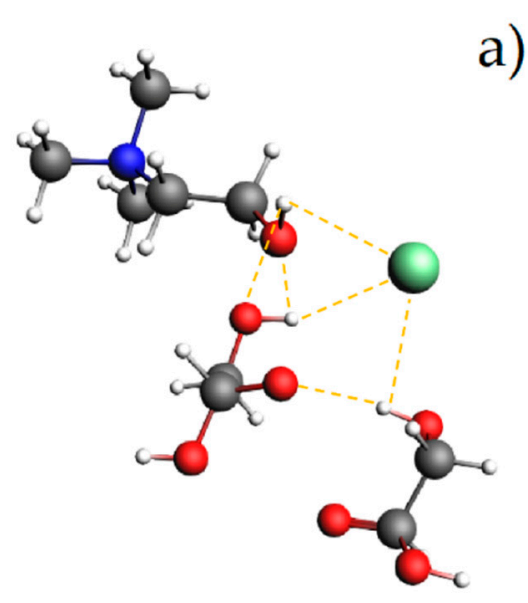

a)

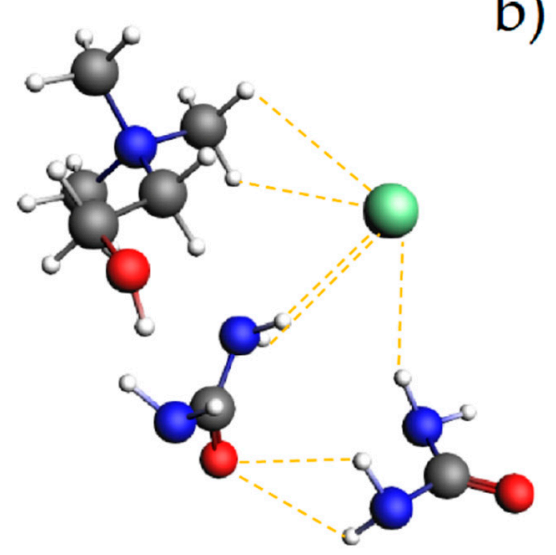

Figure 4. Optimized structures of (a) ChCl:OA (1:2), (b) ChCl:UA (1:2). 


\subsection{1. $\sigma$-Profiles}

The $\sigma$-profile is the most important molecule-specific property because it indicates the probability distribution of the surface area of molecules that have charge density. The $\sigma$-profiles of all contaminants and DESs are presented in Figure 5. In the diagram, the range of surface area over charge density is between -0.025 and $0.025 \mathrm{e}^{-2}$. This range can be divided into three segments, i.e., the non-polar region $\left(-0.0084 \mathrm{e}^{-2}<\sigma<0.0084 \mathrm{e}^{-2}\right)$, the hydrogen bond acceptor (HBA) region $\left(-0.025 \mathrm{e}^{-2}<\sigma\right.$ $\left.<0.0084 \mathrm{e}^{-2}\right)$, and the hydrogen bond donor region (HBD) $\left(0.0084 \mathrm{e}^{-2}<\sigma<0.025 \mathrm{e}^{-2}\right)$. The HBA and HBD regions indicate the potential of the studied molecules to form strong hydrogen bonds. The results indicate that the $\sigma$-profile of $\mathrm{ChCl:U} \mathrm{(1:2)} \mathrm{and} \mathrm{ChCl:OA} \mathrm{(1:2)} \mathrm{almost} \mathrm{overlap} \mathrm{each} \mathrm{other.}$ This means that both DESs have similar properties with regard to molecular interaction. In both DESs, much larger peaks can be observed around negative values, compared to peaks around positive values, which shows more presence of HBA than HBD. The peaks of all siloxanes assume a similar shape and most of the areas are located in the non-polar area $\left(-0.0084 \mathrm{e}^{-2}<\sigma<0.0084 \mathrm{e} \AA^{-2}\right)$, and there are small fragments of siloxane peaks in the HBD region. The opposite results can be observed for carbon dioxide, which may be a hydrogen bond acceptor to a small extent. Similar small areas of hydrogen sulfide peaks are found in the HBA and HBD parts. The $\sigma$-profile results show that the siloxanes have more negative activity coefficient values compared to $\mathrm{CO}_{2}$ and $\mathrm{H}_{2} \mathrm{~S}$.

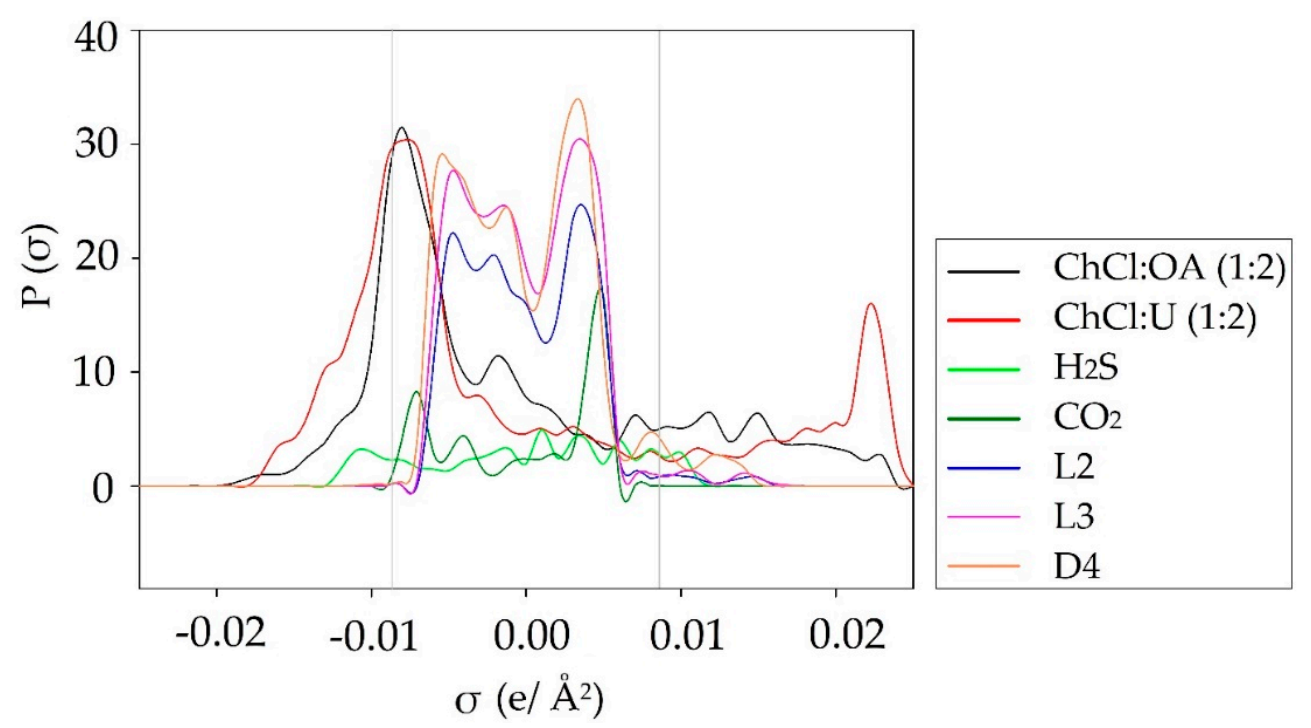

Figure 5. $\sigma$-profiles of $\mathrm{ChCl:OA}(1: 2), \mathrm{ChCl}: \mathrm{U}(1: 2), \mathrm{H}_{2} \mathrm{~S}, \mathrm{CO}_{2}$, and siloxanes (L2, L3, D4).

\subsection{2. $\sigma$-Potential}

The $\sigma$-potential describes the affinity of the DESs to biogas impurities $\left(\mathrm{CO}_{2}, \mathrm{H}_{2} \mathrm{~S}, \mathrm{~L} 2, \mathrm{~L} 3, \mathrm{D} 4\right)$ (Figure 6). The $\sigma$-potential diagram can also be divided into the same three fragments as in the $\sigma$-profile. The higher negative value of $\mu(\sigma)[\mathrm{kcal} / \mathrm{mol} \AA]$ indicates stronger interaction between compounds. On the other hand, the higher positive values of $\mu(\sigma)$ suggest stronger repulsive interactions. 


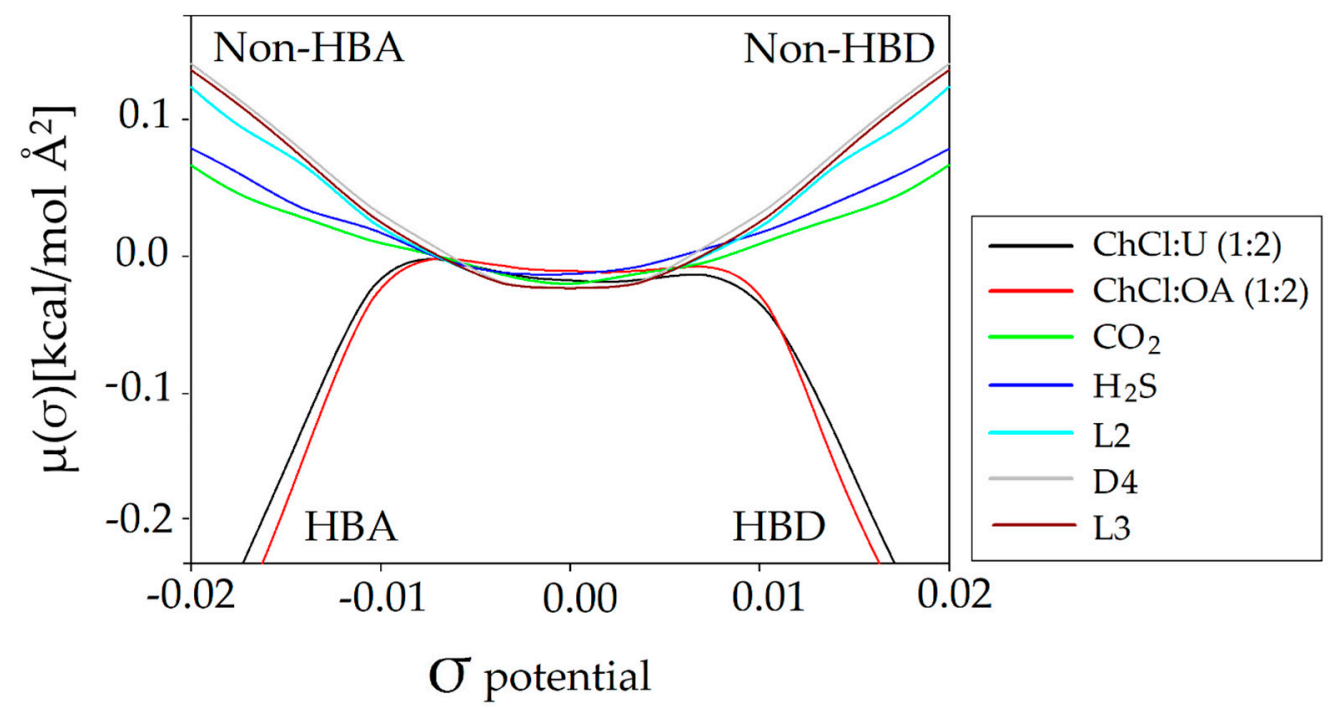

Figure 6. $\sigma$-potential of $\mathrm{ChCl}: \mathrm{U}(1: 2), \mathrm{ChCl}: \mathrm{OA}(1: 2), \mathrm{CO}_{2}, \mathrm{H}_{2} \mathrm{~S}, \mathrm{~L} 2, \mathrm{~L} 3$, and D4.

The graphic results show that all contaminants of the model biogas have parabolic curves of $\sigma$-potential. The negative values of $\mu(\sigma)$ in the non-polar segment indicate the non-polar nature of $\mathrm{CO}_{2}$, $\mathrm{H}_{2} \mathrm{~S}$, and siloxanes. The $\sigma$-potential of $\mathrm{ChCl}: \mathrm{U}(1: 2)$ and $\mathrm{ChCl}: \mathrm{OA}(1: 2)$ show negative values in the HBD, HBA, and non-polar region. This indicates that both DESs will tend to interact with hydrogen bond acceptor and donor surfaces and nonpolar molecules. The positive values of $\sigma$-potential in the HBA and HBD region of all impurities suggest that electrostatic interactions are probably the main driving force of the absorption process. In addition, the high negative value in the non-polar region of the DESs suggests a strong affinity to all biogas impurities. In addition, the similar $\sigma$-potential shape of both DESs suggests similar dissolution capabilities for all of the impurities.

\subsection{Economic Evaluation}

The main factor that determines the success of an investment is the economic cost [71]. The capital and running costs of biogas upgrading technology depend primarily on the size of the installation, type of technology, type of installed devices (their number and power), degree of technological advancement (degree of modernity and automation), system configuration, etc. Therefore, these costs are a function of many factors. The described technology for biogas upgrading assumes that the resulting bio-methane product will meet the quality standards of natural gas [72]. This enables the bio-methane to be introduced into natural gas installations. This is very important from an economic point of view because bio-methane does not require a specially dedicated infrastructure, which increases investment costs.

In order to better compare the cost of applying DESs, the size of installations and process streams were adopted from previous studies [55,56]. Based on an assumed biogas flow rate $\left(813 \mathrm{~m}^{3} / \mathrm{h}\right)$, estimated annual DESs consumption, and assumed biogas composition $\left(\mathrm{CH}_{4}\left(64.9 \% ; 31.0 \% \mathrm{CO}_{2}\right.\right.$; $3.0 \% \mathrm{H}_{2} \mathrm{O} ; 1.04 \% \mathrm{H}_{2} \mathrm{~S}$, and $0,02 \%$ of $\mathrm{L} 2, \mathrm{~L} 3$, and $\left.\mathrm{D} 4[8,54]\right)$ the amount of raw biogas $\left(7.13 \mathrm{Mm}^{3}\right)$ supplied for installation per year was calculated. In addition, methane losses of $5 \%$ during the biogas upgrading process were assumed based on COSMO-RS theoretical calculations. The annual bio-methane production was calculated as $4.27 \mathrm{Mm}^{3}$ per year. Based on the solubility of individual biogas components in DESs, the saturation time of absorbents was calculated using the COSMO-RS model (Table 5). In order to obtain reliable information about the cost of $1 \mathrm{~m}^{3}$ of pure bio-methane, the complete cost analysis including the total investment, operating, and maintenance costs was calculated. 
Table 5. List of individual impurities and their solubility in DESs.

\begin{tabular}{|c|c|c|c|c|c|c|c|}
\hline \multirow{3}{*}{$\begin{array}{l}\text { Type of } \\
\text { Impurities }\end{array}$} & \multirow{2}{*}{$\begin{array}{l}\text { Impurities } \\
\text { Concentration }\end{array}$} & \multirow{2}{*}{$\begin{array}{l}\text { Flow of Individual } \\
\text { Impurities }\end{array}$} & \multirow{2}{*}{$\begin{array}{l}\text { Molar Mass of } \\
\text { Impurities }\end{array}$} & \multicolumn{2}{|c|}{ ChCl:U (1:2) } & \multicolumn{2}{|c|}{ ChCl:OA (1:2) } \\
\hline & & & & Solubility & Saturation Time & Solubility & Saturation Time \\
\hline & {$[\%]$} & {$\left[\mathrm{m}^{3} / \mathrm{h}\right]$} & {$[\mathrm{g} / \mathrm{mol}]$} & $\begin{array}{c}{[\mathrm{mol} / \mathrm{L}} \\
\mathrm{DES}]\end{array}$ & [h] & $\begin{array}{c}{[\mathrm{mol} / \mathrm{L}} \\
\mathrm{DES}]\end{array}$ & {$[\mathrm{h}]$} \\
\hline $\mathrm{CO}_{2}$ & 31.0 & 252.03 & 44.01 & 11.53 & 12.89 & 11.49 & 12.84 \\
\hline $\mathrm{L} 2$ & 0.02 & 0.16 & 162.38 & 1.42 & 21.89 & 0.24 & 3.73 \\
\hline L3 & 0.02 & 0.16 & 236.53 & 0.99 & 20.76 & 0.10 & 2.01 \\
\hline $\mathrm{D} 4$ & 0.02 & 0.16 & 296.62 & 1.09 & 24.51 & 0.14 & 3.12 \\
\hline $\mathrm{H}_{2} \mathrm{~S}$ & 1.04 & 8.46 & 34.10 & 32.93 & 1150.32 & 146.63 & 122.15 \\
\hline
\end{tabular}

\subsubsection{Investment Cost}

The literature review indicated that the process scale of the biogas upgrading technology is the most important factor in the total capital investment cost (TCIC) calculations [73,74].

In this study, an absorption capacity of $427 \mathrm{~m}^{3} / \mathrm{h}$ was obtained for the assumed flow rate of raw biogas, absorption and desorption column dimensions, and 8600 operating hours per year (Table 6). The assumed process parameters enabled the estimation of the individual equipment cost $(E C)$ according to Equation (6). The $E C$ costs (Table 6) include $E C$ for the upgrading biogas section but do not include the biogas production sections. The values presented in Table 6 are average amounts from previous works $[55,56]$. Nevertheless, to minimize the risk of overly optimistic calculations, fluctuations in the market price of individual materials, i.e., steel and electronic components in the years from 2015-2020 were included [75].

Table 6. Estimated costs of equipment of biogas upgrading technology.

\begin{tabular}{llc}
\hline \multicolumn{1}{c}{ Equipment } & \multicolumn{1}{c}{ Description } & Equipment Cost (EC) \pm SD [EUR] \\
\hline Blower & $\begin{array}{l}\text { Introduces biogas into the absorber } \\
\text { Column diameter: } 1 \mathrm{~m}\end{array}$ & $42,000 \pm 3360$ \\
Absorber column & $\begin{array}{l}\text { Column height: } 15 \mathrm{~m} \\
\text { Column diameter: } 1 \mathrm{~m}\end{array}$ & $50,000 \pm 4000$ \\
Stripper column & Column height: $15 \mathrm{~m}$ & $50,000 \pm 4000$ \\
Centrifugal Pump & Pump Power & $46,000 \pm 3680$ \\
Heat Exchanger & Heat Exchanger & $38,000 \pm 3040$ \\
Centrifugal Compressor & Compressor Power & $36,000 \pm 2880$ \\
Dryer & Biogas water collection and disposal & $25,000 \pm 2000$ \\
Unlisted Equipment & & $300,000 \pm 24,000$ \\
Total equipment cost (TEC) & & $587,000 \pm 46,960$ \\
\hline
\end{tabular}

SD—standard deviation.

A total EC cost estimate was necessary to calculate the total capital investment cost (TCIC). TCIC was estimated mainly on the basis of the value of equipment cost (EC) [55]. In addition, statistical data for absorption technologies and laboratory processes scaling data were used for the estimation of the TCIC [55]. The general TCIC analysis for ChCl:U (1:2) and ChCl:OA (1:2) is presented in Table 7. The calculated TCIC for absorption using DESs was in the range of 3,152,088-3,164,929 EUR. The obtained TCIC is comparable to the TCIC of amine scrubber $(3,166,000 \mathrm{EUR})$, pressure swing adsorption (3,140,000 EUR), and membrane separation (3,033,000 EUR) calculated for installations with a capacity of $500 \mathrm{~m}^{3} / \mathrm{h}$ bio-methane. A much lower TCIC was obtained for the water scrubber (2,794,000 EUR) [76]. 
Table 7. The general estimate the total capital investment cost (TCIC) for DES.

\begin{tabular}{lcc}
\hline Parameter & $\begin{array}{c}\text { Cost } \pm \text { SD [EUR] } \\
\text { for ChCl:U (1:2) }\end{array}$ & $\begin{array}{c}\text { Cost } \pm \text { SD [EUR] } \\
\text { for ChCl:OA (1:2) }\end{array}$ \\
\hline & Direct Cost (DC) & \\
Total equipment cost (TEC) & $587,000 \pm 46,960$ & $587,000 \pm 46,960$ \\
Installation instrumentation and control & $610,480 \pm 48,838$ & $610,480 \pm 48,838$ \\
Electrical and heat power & $64,570 \pm 5166$ & $69,950 \pm 5596$ \\
Building and building services and equipment installation & $381,550 \pm 30,524$ & $381,550 \pm 30,524$ \\
Yard improvement & $58,700 \pm 4696$ & $58,700 \pm 4696$ \\
External services & $410,900 \pm 32,872$ & $410,900 \pm 32,872$ \\
Total direct cost (TCD) & $2,113,200 \pm 169,056$ & $2,118,580 \pm 169,486$ \\
& & \\
Engineering and construction site & Indirect Cost (IC) & \\
Law cost & $434,380 \pm 34,750$ & $434,380 \pm 34,750$ \\
Contractor's fee & $23,480 \pm 1878$ & $23,480 \pm 1878$ \\
Incidents & $129,140 \pm 10,331$ & $129,140 \pm 10,331$ \\
Total indirect cost (TCI) & $258,280 \pm 20,662$ & $258,280 \pm 20,662$ \\
& $845,280 \pm 67,622$ & $845,280 \pm 67,622$ \\
Floating capital & & \\
DES batch & & \\
Total other cost (TOC) & Other Cost (OC) & $126,792 \pm 10,143$ \\
Total capital investment cost (TCIC) & $66,816 \pm 5345$ & $74,277 \pm 5942$ \\
\hline
\end{tabular}

SD—standard deviation.

\subsubsection{Operation and Maintenance Cost}

The annual fixed operating costs (FC) included the operation and maintenance cost (OC and MC) of biogas upgrading plants. The OC and MC included the costs of maintenance, operating, labor, and taxation, which are presented in Table 8. The cost of DESs was calculated for the scrubber volume $\left(2.35 \mathrm{~m}^{3}\right)$, which was doubled in order to maintain the continuity of the process.

Table 8. General estimate of the operation cost (OC) and maintenance cost (MC) for DES.

\begin{tabular}{|c|c|c|}
\hline Parameter & $\begin{array}{c}\text { Cost } \pm \text { SD [EUR] } \\
\text { of ChCl:U (1:2) }\end{array}$ & 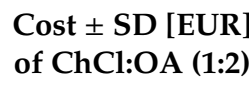 \\
\hline \multicolumn{3}{|l|}{ Fixed Cost (FC) } \\
\hline Regional taxes and insurance & $46,066 \pm 3685$ & $46,066 \pm 3685$ \\
\hline Total fixed cost (TFC) & $46,066 \pm 3685$ & $46,066 \pm 3685$ \\
\hline \multicolumn{3}{|c|}{ Direct Production Cost (DPC) } \\
\hline Maintenance $(\mathrm{M})$ & $69,099 \pm 5528$ & $69,099 \pm 5528$ \\
\hline Salary for the operator (1500 man-hour/year) (SO) (10 Personnel) & $58,320 \pm 4666$ & $58,320 \pm 4666$ \\
\hline Supervision (S) & $8748 \pm 700$ & $8748 \pm 700$ \\
\hline Operating materials & $10,365 \pm 830$ & $10,365 \pm 830$ \\
\hline Changes in electricity cost in the laboratory & $20,425 \pm 1634$ & $20,425 \pm 1634$ \\
\hline Total direct production cost (TDPC) & $166,957 \pm 13,357$ & $166,957 \pm 13,357$ \\
\hline \multicolumn{3}{|c|}{ General Expenses (GE) } \\
\hline Administrative cost & $1313 \pm 105$ & $1313 \pm 105$ \\
\hline Distribution, marketing and R\&D cost & $39,710 \pm 3177$ & $39,710 \pm 3177$ \\
\hline Total general Expenses (TGE) & $41,023 \pm 3282$ & $41,023 \pm 3282$ \\
\hline \multicolumn{3}{|l|}{ DES Cost (DESC) } \\
\hline DES replacement cost & $334,080 \pm 26,726$ & $445,662 \pm 35,653$ \\
\hline Depreciation expense & $3339 \pm 267$ & $339 \pm 267$ \\
\hline Total DES Cost (TDESC) & $337,419 \pm 26,994$ & $449,001 \pm 35,920$ \\
\hline Total operation and maintenance cost (TOC and MC) & $591,465 \pm 47,317$ & $703,047 \pm 56,244$ \\
\hline
\end{tabular}


Due to the different absorption capacity of DES and regeneration cycles, the energy consumption in the absorption processes was different. Based on previous studies, it was assumed that ChCl:U (1:2) and $\mathrm{ChCl:OA} \mathrm{(1:2)} \mathrm{can} \mathrm{be} \mathrm{regenerated} 73$ and 60 times, respectively, without loss of absorption capacity. From an economic and industrial point of view, recycling and reuse of DES after the absorption process is highly desirable because it reduces annual operating costs and the amount of waste. Numerous regeneration cycles can be achieved due to highly reversible absorption, which mainly depends on the structure and thermal stability of DESs. HBDs play the main role in the thermal stability of DESs, which depends mainly on the weak intermolecular interaction. The decomposition temperature of urea in ChCl: $\mathrm{U}$ is about $172.40^{\circ} \mathrm{C}$ [77], while the decomposition temperature of oxalic acid in ChCl:OA is about $134.84^{\circ} \mathrm{C}$ [78]. Both temperatures are higher than the temperature required for regeneration, which is enough to ensure long absorption-desorption cycles. However, the ChCl:OA structure and its lower decomposition temperature result in a slightly lower number of regeneration cycles. After a number of regeneration cycles, DESs must be replaced to further ensure the high quality of bio-methane. The other costs of OC and MC was estimated based on the literature [74,79] and using percentage factors of TCIC. The costs in Table 8 (FC, DPC, GE) are averaged values for selected European Union countries, i.e., Sweden, Germany, France, Norway, and Poland for which standard deviations have been determined. The one-time cost of replacing the absorbent is 66,816 EUR and 74,277 EUR for $\mathrm{ChCl}$ : $\mathrm{U}$ and $\mathrm{ChCl}$ : OA, respectively. Due to the 5-fold ( $\mathrm{ChCl}: \mathrm{U})$ and 6-fold ( $\mathrm{ChCl}$ : OA) exchange of absorbents to ensure the high quality of bio-methane, the total cost of replacement is 334,080 and 445,662 EUR for ChCl:U and ChCl:OA, respectively.

The total OC and MC cost for ChCl:OA (703,047 EUR) is comparable with amine scrubber $(688,000$ EUR) and membrane separation (662,000 EUR), while the total OC and MC cost for ChCl:U (591,465 EUR) is more comparable with water scrubber (513,000 EUR) and pressure swing adsorption (557,000 EUR) [76].

\subsubsection{Economic Comparison of the Overall Biogas Upgrading Process}

It is difficult to clearly estimate the costs of individual technologies due to the differences in the cost of components, materials and utilities, and local conditions. Therefore, is important to consider the total annual cost (TAC) of the biogas upgrading process, which was 982,510 $\pm 78,601 \mathrm{EUR}(\mathrm{ChCl}: \mathrm{U})$ and $1,095,685 \pm 87,654$ EUR (ChCl:OA) in the economic analysis. The TAC cost for $\mathrm{ChCl}: \mathrm{U}$ was very similar to the TAC for pressure swing adsorption $(970,000 \mathrm{EUR})$, while the TAC obtained for ChCl:OA was very similar to the $T A C$ for amine scrubber $(1,104,000 \mathrm{EUR})$ and membrane separation $(1,061,000 \mathrm{EUR})$. The lowest TAC is for the water scrubber ( 880,000 EUR). Based on the above calculations, the unit cost of $1 \mathrm{~m}^{3}$ of pure bio-methane was determined by means of Equation (4). The obtained unit cost of $1 \mathrm{~m}^{3}$ of bio-methane was $0.35 \pm 0.03 \mathrm{EUR} / \mathrm{m}^{3}$ and $0.37 \pm 0.03 \mathrm{EUR} / \mathrm{m}^{3}$ for the physical absorption process using $\mathrm{ChCl}: \mathrm{U}(1: 2)$ and $\mathrm{ChCl}: \mathrm{OA}(1: 2)$, respectively. The unit cost for various biogas treatment technologies can be ordered as follows: amine scrubber $>$ membrane separation $>$ ChCl:OA (1:2) > $\mathrm{ChCl}: \mathrm{U}(1: 2)>\mathrm{PSA}>$ water scrubbing [76] (Table 9). The values include the average standard deviation $(8 \%)$, which was adopted based on the above calculations. Table 9 contains only the total TAC and UC values without standard deviations due to the lack of data from other studies. The main advantage of the innovative method based on DES is the cost of biogas upgrading compared to the most commonly used absorbents. 
Table 9. Comparison of economic analysis.

\begin{tabular}{cccc}
\hline Purification Methods & $\begin{array}{c}\text { Total Annual Cost } \\
(\text { TAC })\end{array}$ & $\begin{array}{c}\text { Unit Cost of } \\
\text { Bio-Methane (UC) }\end{array}$ & Ref. \\
\hline Amine scrubber & $1,104,000 \mathrm{EUR}$ & $0.39 \mathrm{EUR} / \mathrm{m}^{3}$ & {$[56]$} \\
Membrane separation & $1,061,000 \mathrm{EUR}$ & $0.38 \mathrm{EUR} / \mathrm{m}^{3}$ & {$[56]$} \\
ChCl:OA scrubber & $1,095,685 \mathrm{EUR}$ & $0.37 \mathrm{EUR} / \mathrm{m}^{3}$ & This study \\
ChCl:U scrubber & $982,510 \mathrm{EUR}$ & $0.35 \mathrm{EUR} / \mathrm{m}^{3}$ & This study \\
PSA & $970,000 \mathrm{EUR}$ & $0.35 \mathrm{EUR} / \mathrm{m}^{3}$ & {$[56]$} \\
Water scrubbing & $880,000 \mathrm{EUR}$ & $0.33 \mathrm{EUR} / \mathrm{m}^{3}$ & {$[56]$} \\
\hline
\end{tabular}

The application of traditional absorbents (water, amine), requires further biogas refinement operations, which involves additional costs, while the use of DES ensures that high-quality bio-methane is obtained in a one-step process. The obtained results indicate that biogas upgrading technology by means of DESs is a competitive technology for all currently used methods in the industry.

\section{Conclusions}

The study presents low-cost deep eutectic solvents (DES) as potential new sorption materials that enable one-step, effective biogas upgrading. This is a significant advantage compared to the currently used sorbents that are dedicated to removing only selected groups of impurities, which does not guarantee that the biogas will be of sufficient quality. The use of developed sorbents under absorption conditions results in biogas with high-methane gas parameters that meet the parameters for gas injected into the transmission network and transport fuel. In addition, the use of new sorbents based on DESs are highly advantageous from an economic and ecological point of view because the sorbents are synthesized from inexpensive, easily available materials that can be regenerated many times without loss of absorption capacity.

In this study, 23 low-cost DESs composed of quaternary ammonium salts and organic components were investigated. Based on the basic thermodynamic properties, i.e., the activity coefficient, excess enthalpy, and Henry's constant, two DESs (ChCl:U (1:2) and ChCl:OA (1:2)) were selected because they showed the highest dissolution potential of the siloxanes, $\mathrm{CO}_{2}$, and $\mathrm{H}_{2} \mathrm{~S}$. The high affinity of both DESs to all of the main biogas contaminations was confirmed by means of $\sigma$-profiles and $\sigma$-potential analysis. It was shown that the electrostatic interactions between biogas impurities and DESs are the main driving force of the absorption process. For the best DESs, economic analysis simulation was conducted in order to evaluate and compare ChCl:U (1:2) and ChCl:OA (1:2) to each other and to currently available industrial absorbents. The unit cost of DESs depend mainly on the DES structure, which is responsible for its absorption capacity, and regeneration cycles. The unit cost of obtaining $1 \mathrm{~m}^{3}$ of high-quality bio-methane using DESs absorption is comparable to the costs of currently used technologies. However, the proposed biogas upgrading technology offers the possibility of removing $\mathrm{CO}_{2}, \mathrm{H}_{2} \mathrm{~S}$, and siloxanes in one step. This is a significant advantage compared to other commonly used technologies that only remove individual impurities. The obtained results show the great potential of DESs to improve biogas to high-quality bio-methane with properties comparable to natural gas. Such bio-methane could be injected into the natural gas network or used as an alternative to compressed natural gas fuel. However, further experimental research is needed to confirm the obtained results.

Author Contributions: Conceptualization, P.M., and E.S.; methodology, P.M., and E.S.; investigation, P.M., and E.S.; data curation, P.M., and E.S.; writing—original draft preparation, P.M., E.S., J.G.; writing—review and editing, P.M.; visualization, P.M., and E.S.; supervision, J.G. All authors have read and agreed to the published version of the manuscript.

Funding: This research received no external funding.

Conflicts of Interest: The authors declare no conflicts of interest. The funders had no role in the design of the study; in the collection, analyses, or interpretation of data; in the writing of the manuscript, or in the decision to publish the results. 


\section{References}

1. European Biogas Association (EBA). European Biogas Association Annual Report 2019; EBA: Brussels, Belgium, 2019.

2. European Biogas Association (EBA). Statistical Report 2018: Annual Report; EBA: Brussels, Belgium, 2018; Volume 68.

3. Persson, M.; Jonsson, O.; Wellinger, A. Biogas Upgrading To Vehicle Fuel Standards and Grid Injection. IEA Bioenergy Task 2007, 37, 1-34.

4. Andrés, C.; De Guardia, A.; Couvert, A.; Wolbert, D.; Le, S.; Soutrel, I.; Nunes, G. Odor concentration (OC) prediction based on odor activity values (OAVs) during composting of solid wastes and digestates. Atmos. Environ. 2019, 201, 1-12.

5. Papurello, D.; Soukoulis, C.; Schuhfried, E.; Cappellin, L.; Gasperi, F.; Silvestri, S.; Santarelli, M.; Biasioli, F. Monitoring of volatile compound emissions during dry anaerobic digestion of the Organic Fraction of Municipal Solid Waste by Proton Transfer Reaction Time-of-Flight Mass Spectrometry. Bioresour. Technol. 2012, 126, 254-265. [CrossRef] [PubMed]

6. Wasajja, H.; Lindeboom, R.E.F.; van Lier, J.B.; Aravind, P.V. Techno-economic review of biogas cleaning technologies for small scale off-grid solid oxide fuel cell applications. Fuel Process. Technol. 2020, 197, 106215. [CrossRef]

7. Paolini, V.; Petracchini, F.; Segreto, M.; Tomassetti, L.; Naja, N.; Cecinato, A. Environmental impact of biogas: A short review of current knowledge. J. Environ. Sci. Health Part A Toxic Hazard. Subst. Environ. Eng. 2018, 53, 899-906. [CrossRef] [PubMed]

8. Rasi, S.; Veijanen, A.; Rintala, J. Trace compounds of biogas from different biogas production plants. Energy 2007, 32, 1375-1380. [CrossRef]

9. Santos-Clotas, E.; Cabrera-Codony, A.; Martín, M.J. Coupling adsorption with biotechnologies for siloxane abatement from biogas. Renew. Energy 2020, 153, 314-323. [CrossRef]

10. Santos-Clotas, E.; Cabrera-Codony, A.; Boada, E.; Gich, F.; Muñoz, R.; Martín, M.J. Efficient removal of siloxanes and volatile organic compounds from sewage biogas by an anoxic biotrickling filter supplemented with activated carbon. Bioresour. Technol. 2019, 294, 122136. [CrossRef]

11. Liu, Y.H.; Meng, Z.Y.; Wang, J.Y.; Dong, Y.F.; Ma, Z.C. Removal of siloxanes from biogas using acetylated silica gel as adsorbent. Pet. Sci. 2019, 16, 920-928. [CrossRef]

12. Ruiling, G.; Shikun, C.; Zifu, L. Research progress of siloxane removal from biogas. Int. J. Agric. Biol. Eng. 2017, 10, 30-39.

13. Shen, M.; Zhang, Y.; Hu, D.; Fan, J.; Zeng, G. A review on removal of siloxanes from biogas: With a special focus on volatile methylsiloxanes. Environ. Sci. Pollut. Res. 2018, 25, 30847-30862. [CrossRef] [PubMed]

14. Xiao, Y.; Yuan, H.; Pang, Y.; Chen, S.; Zhu, B.; Zou, D.; Ma, J.; Yu, L.; Li, X. CO2 Removal from Biogas by Water Washing System. Chin. J. Chem. Eng. 2014, 22, 950-953. [CrossRef]

15. Mandal, B.P.; Biswas, A.K.; Bandyopadhyay, S.S. Selective absorption of H2S from gas streams containing $\mathrm{H} 2 \mathrm{~S}$ and $\mathrm{CO} 2$ into aqueous solutions of $\mathrm{N}$-methyldiethanolamine and 2-amino-2-methyl-1-propanol. Sep. Purif. Technol. 2004, 35, 191-202. [CrossRef]

16. Jassim, M.S.; Rochelle, G.; Eimer, D.; Ramshaw, C. Carbon Dioxide Absorption and Desorption in Aqueous Monoethanolamine Solutions in a Rotating Packed Bed. Ind. Eng. Chem. Res. 2007, 46, 2823-2833. [CrossRef]

17. $\mathrm{Xu}$, H.J.; Zhang, C.F.; Zheng, Z.S. Solubility of hydrogen sulfide and carbon dioxide in a solution of methyldiethanolamine mixed with ethylene glycol. Ind. Eng. Chem. Res. 2002, 41, 6175-6180. [CrossRef]

18. Privalova, E.; Nurmi, M.; Marañón, M.S.; Murzina, E.V.; Mäki-arvela, P.; Eränen, K.; Murzin, D.Y.; Mikkola, J. $\mathrm{CO}_{2}$ removal with 'switchable' versus 'classical' ionic liquids. Sep. Purif. Technol. 2012, 97, 42-50. [CrossRef]

19. Gao, J.; Cao, L.; Dong, H.; Zhang, X.; Zhang, S. Ionic liquids tailored amine aqueous solution for pre-combustion $\mathrm{CO}_{2}$ capture: Role of imidazolium-based ionic liquids. Appl. Energy 2015, 154, 771-780. [CrossRef]

20. Shiflett, M.B.; Yokozeki, A. Solubilities and Diffusivities of Carbon Dioxide in Ionic Liquids: [bmim] [PF 6] and [bmim] [BF 4]. Ind. Eng. Chem. Res. 2005, 4453-4464. [CrossRef]

21. Jou, F.Y.; Mather, A.E. Solubility of hydrogen sulfide in [bmim][PF 6]. Int. J. Thermophys. 2007, 28, 490-495. [CrossRef] 
22. Pomelli, C.S.; Chiappe, C.; Vidis, A.; Laurenczy, G.; Dyson, P.J. Influence of the interaction between hydrogen sulfide and ionic liquids on solubility: Experimental and theoretical investigation. J. Phys. Chem. B 2007, 111, 13014-13019. [CrossRef]

23. Rahmati-Rostami, M.; Ghotbi, C.; Hosseini-Jenab, M.; Ahmadi, A.N.; Jalili, A.H. Solubility of H2S in ionic liquids [hmim][PF6], [hmim][BF4], and [hmim][Tf2N]. J. Chem. Thermodyn. 2009, 41, 1052-1055. [CrossRef]

24. Zhang, X.; Zhang, X.; Dong, H.; Zhao, Z.; Zhang, S.; Huang, Y. Carbon capture with ionic liquids: Overview and progress. Energy Environ. Sci. 2012, 5, 6668-6681. [CrossRef]

25. Xie, Y.; Zhang, Y.; Lu, X.; Ji, X. Energy consumption analysis for CO2 separation using imidazolium-based ionic liquids. Appl. Energy 2014, 136, 325-335. [CrossRef]

26. Thuy Pham, T.P.; Cho, C.W.; Yun, Y.S. Environmental fate and toxicity of ionic liquids: A review. Water Res. 2010, 44, 352-372. [CrossRef]

27. Abbott, A.P.; Capper, G.; Davies, D.L.; Rasheed, R.K.; Tambyrajah, V. Novel Solvent Properties of Choline Chloride/Urea Mixtures. Chem. Commun. 2003, 0, 70-71. [CrossRef]

28. Azizi, N.; Dezfooli, S.; Khajeh, M.; Hashemi, M.M. Efficient deep eutectic solvents catalyzed synthesis of pyran and benzopyran derivatives. J. Mol. Liq. 2013, 186, 76-80. [CrossRef]

29. Abbott, A.P.; Barron, J.C.; Ryder, K.S.; Wilson, D. Eutectic-Based Ionic Liquids with Metal-Containing Anions and Cations. Chem. Eur. J. 2007, 13, 6495-6501. [CrossRef]

30. Mainar, A.R.; Iruin, E.; Colmenares, L.C.; Kvasha, A.; de Meatza, I.; Bengoechea, M.; Leonet, O.; Boyano, I.; Zhang, Z.; Blazquez, J.A. An overview of progress in electrolytes for secondary zinc-air batteries and other storage systems based on zinc. J. Energy Storage 2018, 15, 304-328. [CrossRef]

31. Werner, S.; Haumann, M.; Wasserscheid, P. Ionic Liquids in Chemical Engineering. Annu. Rev. Chem. Biomol. Eng. 2010, 1, 203-230. [CrossRef]

32. Sowmiah, S.; Srinivasadesikan, V.; Tseng, M.C.; Chu, Y.H. On the Chemical Stabilities of Ionic Liquids. Molecules 2009, 14, 3780-3813. [CrossRef]

33. Dai, Y.; Van Spronsen, J.; Witkamp, G.J.; Verpoorte, R.; Choi, Y.H. Ionic liquids and deep eutectic solvents in natural products research: Mixtures of solids as extraction solvents. J. Nat. Prod. 2013, 76, 2162-2173. [CrossRef] [PubMed]

34. Turosung, S.N.; Ghosh, B. Application of Ionic Liquids in the Upstream oil Industry-A Review. Int. J. Petrochem. Res. 2017, 1, 50-60. [CrossRef]

35. Smith, E.L.; Abbott, A.P.; Ryder, K.S. Deep Eutectic Solvents (DESs) and Their Applications. Chem. Rev. 2014, 114, 11060-11082. [CrossRef] [PubMed]

36. Vanda, H.; Dai, Y.; Wilson, E.G.; Verpoorte, R.; Choi, Y.H. Green solvents from ionic liquids and deep eutectic solvents to natural deep eutectic solvents. Comptes Rendus Chim. 2018, 21, 628-638. [CrossRef]

37. Marcus, Y. Estimation of the Critical Temperatures of Some More Deep Eutectic Solvents from Their Surface Tensions. Adv. Mater. Sci. Eng. 2018, 2018, 2-5. [CrossRef]

38. Makoś, P.; Słupek, E.; Gębicki, J. Extractive detoxification of feedstocks for the production of biofuels using new hydrophobic deep eutectic solvents - Experimental and theoretical studies. J. Mol. Liq. 2020, in press.

39. Makoś, P.; Przyjazny, A.; Boczkaj, G. Hydrophobic deep eutectic solvents as "green" extraction media for polycyclic aromatic hydrocarbons in aqueous samples. J. Chromatogr. A 2018, 1570, 28-37. [CrossRef] [PubMed]

40. Makoś, P.; Boczkaj, G. Deep eutectic solvents based highly efficient extractive desulfurization of fuels-Eco-friendly approach. J. Mol. Liq. 2019, 111916. [CrossRef]

41. Makoś, P.; Fernandes, A.; Przyjazny, A.; Boczkaj, G. Sample preparation procedure using extraction and derivatization of carboxylic acids from aqueous samples by means of deep eutectic solvents for gas chromatographic-mass spectrometric analysis. J. Chromatogr. A 2018, 1555, 10-19. [CrossRef] [PubMed]

42. Zhong, F.-Y.; Huang, K.; Peng, H.-L. Solubilities of ammonia in choline chloride plus urea at (298.2-353.2) K and (0-300) kPa. J. Chem. Thermodyn. 2019, 129, 5-11. [CrossRef]

43. Zhang, K.; Hou, Y.; Wang, Y.; Wang, K.; Ren, S.; Wu, W. Efficient and Reversible Absorption of CO2 by Functional Deep Eutectic Solvents. Energy Fuels 2018, 32, 7727-7733. [CrossRef]

44. Moura, L.; Moufawad, T.; Ferreira, M.; Bricout, H.; Tilloy, S.; Monflier, E.; Costa Gomes, M.F.; Landy, D.; Fourmentin, S. Deep eutectic solvents as green absorbents of volatile organic pollutants. Environ. Chem. Lett. 2017, 15, 747-753. [CrossRef] 
45. Słupek, E.; Makoś, P.; Gębicki, J. Deodorization of model biogas by means of novel non-ionic deep eutectic solvent. Arch. Environ. Prot. 2020, 46, 41-46.

46. Słupek, E.; Makoś, P. Absorptive Desulfurization of Model Biogas Stream Using Choline Chloride-Based Deep Eutectic Solvents. Sustainability 2020, 12, 1619. [CrossRef]

47. Zhang, Y.; Ji, X.; Xie, Y.; Lu, X. Thermodynamic analysis of CO2 separation from biogas with conventional ionic liquids. Appl. Energy 2018, 217, 75-87. [CrossRef]

48. Ali, E.; Hadj-Kali, M.K.; Mulyono, S.; Alnashef, I. Analysis of operating conditions for CO2 capturing process using deep eutectic solvents. Int. J. Greenh. Gas Control 2016, 47, 342-350. [CrossRef]

49. Makoś, P.; Słupek, E.; Małachowska, A. Silica Gel Impregnated by Deep Eutectic Solvents for Adsorptive Removal of BTEX from Gas Streams. Materials 2020, 13, 1894. [CrossRef]

50. Häckl, K.; Kunz, W. Some aspects of green solvents. Comptes Rendus Chim. 2018, 21, 572-580. [CrossRef]

51. Del Olmo, L.; Lõpez, R.; García De La Vega, J.M. Effect of the molecular structure in the prediction of thermodynamic properties for 1-butyl-3-methylimidazolium chloride ionic liquid. Int. J. Quantum Chem. 2013, 113, 852-858. [CrossRef]

52. Pye, C.C.; Ziegler, T. An implementation of the conductor-like screening model of solvation within the Amsterdam density functional package. Theor. Chem. Acc. 1999, 101, 396-408. [CrossRef]

53. AMS 2019.3 COSMO-RS, SCM, Theoretical Chemistry. Vrije Universiteit: Amsterdam, The Netherlands; Available online: http://www.scm.com (accessed on 4 May 2020).

54. Rasi, S.; Läntelä, J.; Rintala, J. Upgrading landfill gas using a high pressure water absorption process. Fuel 2014, 115, 539-543. [CrossRef]

55. Ma, C.; Liu, C.; Lu, X.; Ji, X. Techno-economic analysis and performance comparison of aqueous deep eutectic solvent and other physical absorbents for biogas upgrading. Appl. Energy 2018, 225, 437-447. [CrossRef]

56. Xie, Y.; Björkmalm, J.; Ma, C.; Willquist, K.; Yngvesson, J.; Wallberg, O.; Ji, X. Techno-economic evaluation of biogas upgrading using ionic liquids in comparison with industrially used technology in Scandinavian anaerobic digestion plants. Appl. Energy 2018, 227, 742-750. [CrossRef]

57. Scholz, M.; Frank, B.; Stockmeier, F.; Falß, S.; Wessling, M. Techno-economic analysis of hybrid processes for biogas upgrading. Ind. Eng. Chem. Res. 2013, 52, 16929-16938. [CrossRef]

58. Guthrie, H.M. Capital cost estimation for the chemical and process industries. Chem. Eng. 1969, 32, 114-142.

59. Euro Statistic Explained Electricity Prices First Semester of 2017_2019 (EUR Per kWh). Available online: https://ec.europa.eu/eurostat/statistics-explained/index.php?title=File:Electricity_prices,_first_ semester_of_2017-2019_(EUR_per_kWh).png (accessed on 4 May 2020).

60. Alibaba.com Choline Chloride. Available online: https://www.alibaba.com/product-detail/choline-chlorideCAS-67-48-1_62448780792.html?spm=a2700.7724857.normalList (accessed on 4 May 2020).

61. Alibaba.com Urea. Available online: https://www.alibaba.com/product-detail/price-per-ton-urea-2019-high_ 60456580510.html?spm=a2700.7724857.normalList.188.c2e9746du64Jbd (accessed on 4 May 2020).

62. Alibaba.com Oxalic Acid. Available online: https://www.alibaba.com/product-detail/99-6-min-OxalicAcid-h2c2o4_60767148271.html?spm=a2700.7724857.normalList.11.27d05ea2G45DWC\&s=p\&bypass=true (accessed on 4 May 2020).

63. De Hullu, J.; Massen, J.L.W.; van Meel, P.A.; Shazad, S.; Vaessen, J.M.P. Comparing Different Biogas Upgrading Techniques-Report; Eindhoven University of Technology: Eindhoven, The Netherlands, 2008.

64. Chu, Y.; He, X. MoDoop: An Automated Computational Approach for COSMO-RS Prediction of Biopolymer Solubilities in Ionic Liquids. ACS Omega 2019, 4, 2337-2343. [CrossRef]

65. Makoś, P.; Słupek, E.; Gębicki, J. Hydrophobic deep eutectic solvents in microextraction techniques-A review. Microchem. J. 2020, 152. [CrossRef]

66. Han, J.; Dai, C.; Yu, G.; Lei, Z. Parameterization of COSMO-RS model for ionic liquids. Green Energy Environ. 2018, 3, 247-265. [CrossRef]

67. Mu, T.; Rarey, J.; Gmehling, J. Performance of COSMO-RS with sigma profiles from different model chemistries. Ind. Eng. Chem. Res. 2007, 46, 6612-6629. [CrossRef]

68. Mullins, E.; Oldland, R.; Liu, Y.A.; Wang, S.; Sandler, S.I.; Chen, C.C.; Zwolak, M.; Seavey, K.C. Sigma-profile database for using COSMO-based thermodynamic methods. Ind. Eng. Chem. Res. 2006, 45, 4389-4415. [CrossRef] 
69. Salleh, Z.; Wazeer, I.; Mulyono, S.; El-blidi, L.; Hashim, M.A.; Hadj-Kali, M.K. Efficient removal of benzene from cyclohexane-benzene mixtures using deep eutectic solvents-COSMO-RS screening and experimental validation. J. Chem. Thermodyn. 2017, 104, 33-44. [CrossRef]

70. Liu, Y.-R.; Thomsen, K.; Nie, Y.; Zhang, S.-J.; Meyer, A.S. Predictive screening of ionic liquids for dissolving cellulose and experimental verification. Green Chem. 2016, 18, 6246-6254. [CrossRef]

71. Hosseinipour, S.A.; Mehrpooya, M. Comparison of the biogas upgrading methods as a transportation fuel. Renew. Energy 2019, 130, 641-655. [CrossRef]

72. Ryckebosch, E.; Drouillon, M.; Vervaeren, H. Techniques for transformation of biogas to biomethane. Biomass Bioenergy 2011, 35, 1633-1645. [CrossRef]

73. Petersson, A.; Holm-nielsen, J.B.; Baxter, D. Biogas upgrading technologies-Developments and innovations. IEA Bioenergy Task 2009, 37.

74. Warren, W.K.E.H. A Techno-economic Comparison of Biogas Upgrading Technologies in Europe. Master's Thesis, Jyväskylän yliopisto-University of Jyväskylä, Jyväskylä, Finland, 2012; p. 44.

75. Trading Economics. Available online: https://tradingeconomics.com/commodity/steel?fbclid= IwAR12n6kfQegnqpqrIPqJZ47gjDUh2Q7OIt9BChQosYiJnZSHskCDwczPqJ8 (accessed on 21 May 2020).

76. Stürmer, B.; Kirchmeyr, F.; Kovacs, K.; Hofmann, F.; Collins, D.; Ingremeau, C.; Stambasky, J. Technical-Economic Analysis for Determining the Feasibility Threshold for Tradable Biomethane Certificates-Report; European Renewable Gas Registry: Brussels, Belgium, 2016; pp. 1-24.

77. Chen, W.; Xue, Z.; Wang, J.; Jiang, J.; Zhao, X.; Mu, T. Investigation on the thermal stability of deep eutectic solvents. Wuli Huaxue Xuebao/Acta Phys. Chim. Sin. 2018, 34, 904-911. [CrossRef]

78. Haz, A.; Strizincova, P.; Majova, V.; Skulcova, A.; Jablonsky, M. Thermal stability of selected deep eutectic solvents. Int. J. Recent Sci. Res. 2016, 7, 14441-14444.

79. Brown, R.C.; Brown, T.R. Biorenewable Resources: Engineering New Products from Agriculture: Second Edition. Biorenew. Resour. Eng. New Prod. Agric. Second Ed. 2014, 9781118524, 1-375.

(C) 2020 by the authors. Licensee MDPI, Basel, Switzerland. This article is an open access article distributed under the terms and conditions of the Creative Commons Attribution (CC BY) license (http://creativecommons.org/licenses/by/4.0/). 